\title{
Characteristics of non-small-cell lung cancer with interstitial pneumonia: variation in cancer location, histopathology, and frequency of postoperative acute exacerbations in interstitial pneumonia
}

Kazumasa Ogawa ${ }^{1,2,3,4^{*}}$ (D), Hironori Uruga ${ }^{1,2,5}$, Takeshi Fujii, ${ }^{2,5}$, Sakashi Fujimori ${ }^{1}$, Tadasu Kohno ${ }^{1,6}$, Atsuko Kurosaki ${ }^{1,7}$, Kazuma Kishi ${ }^{1,2,8}$ and Shinji $\mathrm{Abe}^{3}$

\begin{abstract}
Background: Non-small-cell lung cancer (NSCLC) has been reported to develop in patients with interstitial pneumonia (IP); however, clinical, radiological, and pathological features remain to be elucidated.

Methods: We retrieved the records of 120 consecutive NSCLC patients associated with IP who underwent surgery at Toranomon Hospital between June 2011 and May 2017. We classified the patients into three groups according to NSCLC location using high-resolution computed tomography: group A, within a fibrotic shadow and/or at the interface of a fibrotic shadow and normal lung; group B, within emphysematous tissue and/or at the interface of emphysematous tissue and normal lung; and group C, within normal lung. In 64 patients, programmed death ligand-1 (PD-L1) status was assessed with immunohistostaining.
\end{abstract}

Results: Most of the patients (89; 70\%) were classified as group A. This group tended to have squamous cell carcinoma with the usual interstitial pneumonia (UIP). These cancers were located mainly in the lower lobes and seven of the eight postoperative acute exacerbations (pAE) of IP developed in this group. NSCLC in the group B were mainly squamous cell carcinomas located in the upper lobes. No patient with PD-L1 negative was classified into group B. None of the patients in group C showed UIP. and most of the cancers were adenocarcinoma. The frequency of epidermal growth factor receptor mutation-positive NSCLC was the highest in this group.

Conclusions: The three groups each showed characteristic features in terms of tumor location, histopathology, PDL1 expression, and frequency of pAEof IP.

Keywords: Interstitial lung disease, Non-small-cell lung cancer, Video-assisted thoracic surgery, Acute exacerbation, Cancer location, Pulmonary emphysema

\footnotetext{
* Correspondence: kaz_sap_tok@yahoo.co.jp

'Department of Respiratory Medicine, Respiratory Center, Toranomon

Hospital, 2-2-2, Toranomon, Minato-ku, Tokyo, Japan

${ }^{2}$ Okinaka Memorial Institute for Medical Research, 2-2-2, Toranomon,

Minato-ku, Tokyo, Japan

Full list of author information is available at the end of the article
}

\section{$\triangle B M C$}

C C The Author(s). 2020 Open Access This article is licensed under a Creative Commons Attribution 4.0 International License, which permits use, sharing, adaptation, distribution and reproduction in any medium or format, as long as you give appropriate credit to the original author(s) and the source, provide a link to the Creative Commons licence, and indicate if changes were made. The images or other third party material in this article are included in the article's Creative Commons licence, unless indicated otherwise in a credit line to the material. If material is not included in the article's Creative Commons licence and your intended use is not permitted by statutory regulation or exceeds the permitted use, you will need to obtain permission directly from the copyright holder. To view a copy of this licence, visit http://creativecommons.org/licenses/by/4.0/ The Creative Commons Public Domain Dedication waiver (http://creativecommons.org/publicdomain/zero/1.0/) applies to the data made available in this article, unless otherwise stated in a credit line to the data. 


\section{Background}

For 35 years, lung cancer has been one of the leading causes of cancer-related death in developed countries [1]. Lung cancers have higher incidence rates in patients with interstitial pneumonia (IP) than in those without IP [2-7]. There are various treatment options for lung cancers, including surgical treatment, radiotherapy, chemotherapy, and immunotherapy; however, there is a concern that these may result in the acute exacerbation (AE) of preexisting IP [7-11]. An official joint statement of the American Thoracic Society, European Respiratory Society, Japanese Respiratory Society, and Latin American Thoracic Association (ATS/ERS/JRS/ALAT) [12] weakly recommends steroid therapy for AE of IP; nevertheless, managing $\mathrm{AE}$ of IP remains challenging because of the extremely high mortality rate [7, 8, 13-15].

Although there have been reports of the outcomes of surgical treatment for lung cancer patients with IP $[8,16-$ $18]$, most of these studies were small and retrospective, without long-term outcomes. One of these studies investigated risk factors for the development of postoperative AE of IP [8]. However, as yet there are no established strategies or drugs for preventing AE of IP [7, 8, 19].

The radiological and pathological features of lung cancers associated with IP have not yet been fully elucidated. Some studies have reported that lung cancers with IP tended to develop inside honeycombing in the lungs or at the interface of the honeycombing and normal lung in the lower lobes [7, 20-22], although some lung cancers developed in the upper lobes apart from fibrotic changes [23, 24]. The main pathological type associated with IP is squamous cell carcinoma; in contrast, the main pathological type for patients without IP is adenocarcinoma $[7,25]$. The expression of programmed cell death ligand 1(PD-L1) in patients of lung cancer with IP have been also assessed in a few studies and has been mainly reported to be positive [26, 27]. However, studies investigating radiological and pathological features of lung cancers associated with IP have been small and retrospective, and these features require further clarification.

We speculate that lung cancer associated with IP is not a homogeneous disease. Some lung cancers develop within honeycombing in the lungs, whereas others develop within emphysematous tissue in the upper lobes or in normal lung away from fibrotic changes or emphysema. We hypothesized that the features of lung cancers with IP vary according to the location where they develop, as a result of different underlying mechanisms. Additionally, the frequency of postoperative AE of IP may differ according to cancer location. This study aimed to analyze 120 patients with non-small-cell lung cancer (NSCLC) who had IP to verify these hypotheses.

\section{Methods}

This retrospective study was based on the records of patients with NSCLC who underwent surgical treatment at our hospital between June 2011 and May 2017, retrieved from our institutional database. Patients who underwent only surgical biopsy were excluded. Among the 1414 patients with NSCLC, 120 had IP as an underlying condition. These 120 patients were included in our analysis.

The study was approved by the Institutional Review Board of Toranomon Hospital (1329-H/B and 1447). Patient consent was obtained by using informed consent documents with an opt-out process.

In this study, we categorized IP-associated NSCLCs into three groups according to the location of cancer development determined by high-resolution computed tomography (HRCT). We also evaluated the clinical courses, treatment outcomes (including long-term outcomes), and pathological findings in each group.

The patient's medical charts, laboratory data, pulmonary function test results, HRCT findings, and histopathological findings were reviewed using the most recent results available prior to the surgical treatment. The data and outcomes were followed until July 2019.

In this study, IP diagnoses were established using HRCT. The radiological pattern of IP was classified into the usual interstitial pneumonia (UIP) pattern or non-UIP pattern. The UIP pattern required subpleural, basal predominance, reticular abnormality, and the absence of the non-UIP pattern features on HRCT. Honeycombing or traction bronchiectasis was not essential for the UIP pattern in the present study. The non-UIP pattern required one of the following: upper or mid-lung predominance, peribronchovascular predominance, extensive groundglass abnormality, profuse micronodules, discrete cysts, diffuse mosaic attenuation, air-trapping, and consolidation in bronchopulmonary segments [12].

The severity of IP was calculated using the GenderAge-Physiology (GAP) index [28], a multidimensional index and staging system for idiopathic pulmonary fibrosis (IPF). We adapted the GAP index for the patients whose IP was not IPF.

AE of IP were diagnosed using the definition proposed by Collard et al. [29], which requires that all of the following four conditions be met: a previous or concurrent diagnosis of IPF; acute deterioration or the development of dyspnea, typically for less than one month in duration; on CT imaging, new bilateral ground-glass opacity and/ or consolidation superimposed on a background of IP consistent with the UIP pattern; and deterioration not fully explained by cardiac failure or fluid overload. In this study, we adapted this definition for patients whose IP was not IPF or whose HRCT images did not exhibit the UIP pattern. Any AE of IP that developed within one month of surgery was considered to be a postoperative AE of IP.

We classified lung cancers with IP into three groups according to the location where the cancer developed 
using HRCT: group A, within a fibrotic shadow and/or at the interface of a fibrotic shadow and normal lung; group B, within emphysematous tissue and/or at the interface of emphysematous tissue and normal lung; and group $\mathrm{C}$, within normal lung, away from reticular shadows or emphysema (Figs. 1, 2, 3).

The histological pattern of the tumor was classified according to the World Health Organization's Classification of Tumors of the Lung, Pleura, Thymus, and Heart, 4th edition [30], and the cancer was staged according to the American Joint Committee of Cancer's Cancer Staging Handbook, 7th edition [31].

The PD-L1 status of 68 lung cancers in 64 patients who gave written informed consent was assessed by immunohistostaining using 22C3 antibody concentrate on the Dako ASL48 platform. PD-L1 expression was determined according to a tumor proportion score (TPS), which is defined as the percentage of tumor cell-positive membrane staining, and scored independently by one pathologist who specializes in pulmonary pathology and one pulmonologist who specializes in pulmonary pathology; both were blinded to the clinical data. The score was classified into three levels: TPS $<1 \%$, TPS $1-49 \%$, and TPS $\geq 50 \%$ (Fig. 4).

The statistical analysis was performed using SPSS version 26.0 (IBM Corp., Armonk, NY). The comparisons of characteristics between the patients with and without the AE of IP were evaluated using the Mann-Whitney U test and chi-square test, as appropriate. Survival time was analyzed with the Kaplan-Meier method. Statistical significance was defined as $p<0.05$.

\section{Results}

\section{Clinical results}

The clinical and demographic characteristics of the 120 patients (97 men, 23 women; median age, 74 years), including details of their cancers and treatments, are summarized in Table 1 . In total there were 128 lung cancers, and eight patients underwent surgical treatment for double de novo lung cancers at once. The median follow-up time was 905 days.

All participating patients had IP as an underlying disease, and 101 (84\%) of these patients had an idiopathic etiology. Video-assisted thoracic surgery (VATS) alone was used for 116 patients (97\%); the other four patients underwent open surgery combined with VATS. Lobectomy was performed in 83 patients, segmentectomy in 23 patients and wedge resection in 14 patients, respectively. Table 1 summarizes the pathological staging of the lung cancer; $46(38 \%)$ of the patients were at stage IA. The undetermined pathological staging was mainly because of wedge resection. Table 2 summarizes the histological types and mutation status of the 128 lung cancers. The most common histological type was squamous cell carcinoma, accounting for 67 (52\%) of the cancers. Activating epidermal growth factor receptor mutations were detected in four patients among 111 tested cancers.

Table 3 compares characteristics between the patients who experienced AE of IP and those who did not. Eight patients (7\%) experienced postoperative AE of IP. The median time from surgery to the AE was 16.5 days, and the median survival time after surgery of these patients was 176 days. Compared to the other patients, the patients who developed AE of IP tended to have undergone lobectomy $(100 \%$ vs. $67 \%, p=0.047)$ and to have lower percent predicted vital capacity (\%VC; $88.0 \%$ vs. $100 \%, p=0.044)$.

Postoperative lung cancer recurrence was experienced by $29(24 \%)$ of the patients. Best supportive care was the most frequently chosen option for these patients (used for 17 patients, 59\%), followed by chemotherapy (10, $34 \%)$, and other options (2, 7\%). The median survival time from the surgery of the patients with recurrence of lung cancer was 1116 days.

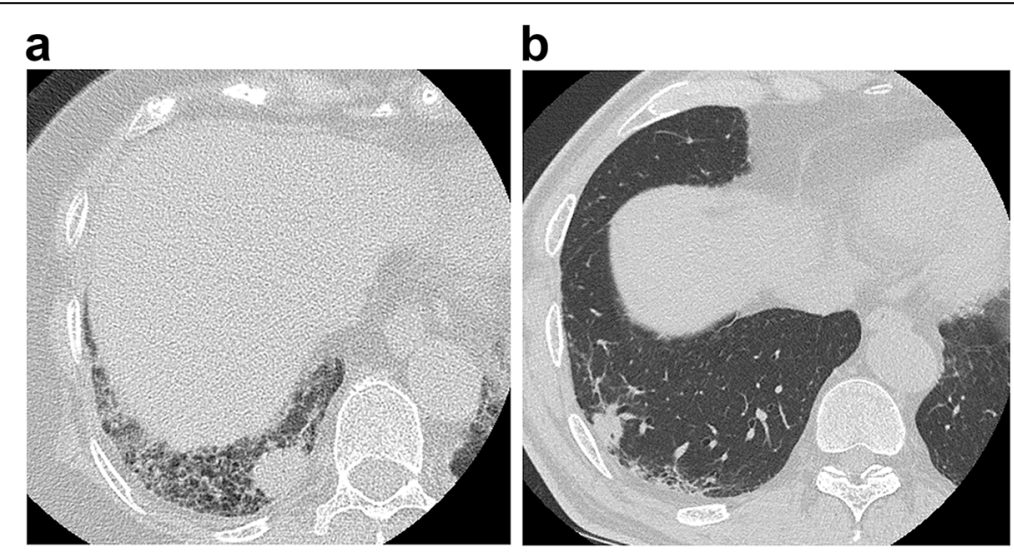

Fig. 1 Lung cancer in midst of fibrotic shadow and/or interface of fibrotic shadow and normal lung. These are examples of computed tomography findings for lung cancers in the fibrotic shadow 


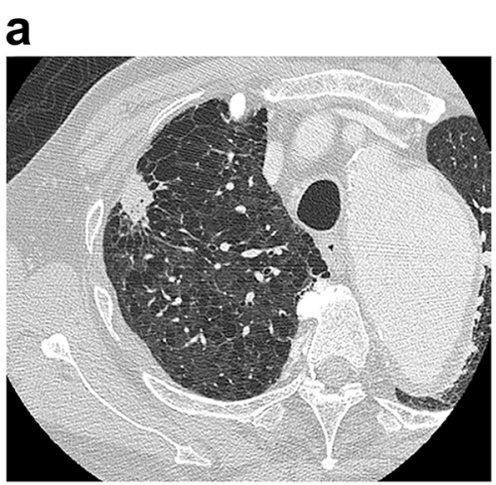

b

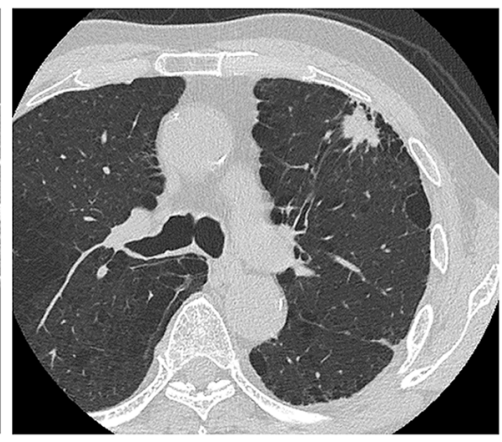

Fig. 2 Lung cancer in midst of emphysema and/or interface of emphysema and normal lung. These are examples of computed tomography findings for lung cancers in midst of emphysema

Figure 5 shows the Kaplan-Meier survival curve for all 120 patients. The median survival time was 2011 days. The one-, three-, and five-year survival rates were 87.5, 72.4 , and $58.9 \%$, respectively. The causes of death were IP in $14(12 \%)$ of the patients, lung cancer in $14(12 \%)$, and other in $10(8 \%)$.

The clinical outcomes for each pathological stage of cancer are shown in Table 4. Among the 46 patients with stage IA cancer, four (9\%) experienced recurrence; the five-year survival rate for this stage was $69 \%$.

\section{Radiological results}

Table 5 compares the clinical and pathological findings between groups A, B, and C (as defined in the Methods section). Of the 128 lung cancers, $89(70 \%)$ were classified as group A, $29(23 \%)$ as group B, and $10(8 \%)$ as group C. There was a significant difference between the groups in patients with UIP pattern $(p=0.002)$ and the proportion of IPF patients $(p=0.014)$. The UIP pattern was exhibited by $49(55 \%)$ patients in group A but by none in group $\mathrm{C}$. All the patients in group B had pulmonary emphysema, but only $25 \%$ of the patients in group $C$ had pulmonary emphysema $(p<0.001)$. There was also a significant difference between the groups in the histopathological type of cancer, specifically the proportion that were adenocarcinoma $(p=0.01)$.

Group A included 29 (33\%) adenocarcinomas and 49 (55\%) squamous cell carcinomas and group B included 9 (31\%) adenocarcinomas and 16 (55\%) squamous cell carcinomas, whereas group C included 8 (80\%) adenocarcinomas and $2(20 \%)$ squamous cell carcinomas. EGFR mutations were most frequently detected in the patients in group $\mathrm{C}$ $(p=0.047)$. A further significant difference was observed in the location of the cancers $(p<0.001)$. In group $\mathrm{A}, 84 \%$ of the cancers were in the lower lobe; in group B, $90 \%$ of the cancers were in the upper lobe; and in group $\mathrm{C}$, the cancers

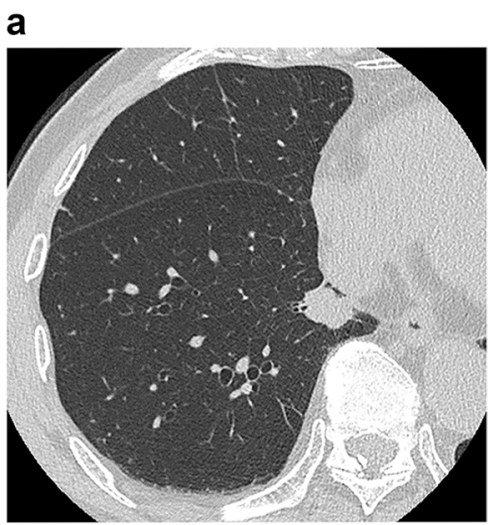

b

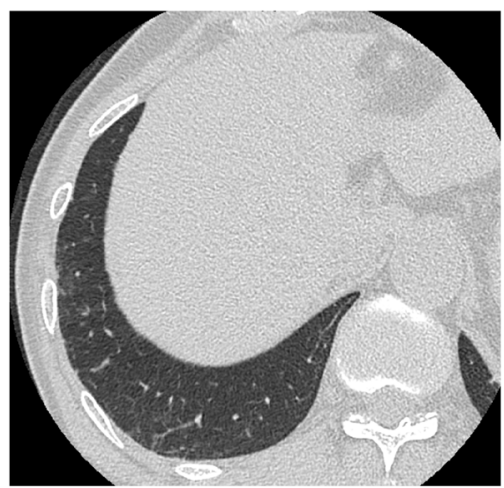

Fig. 3 Lung cancer in the normal lung (apart from reticular shadows or emphysema). a The example of computed tomography findings in the lung of a patient with lung cancer. $\mathbf{b}$ This is an image showing rest of the lung of patient with fibrosis in Fig. 3a. The image shows mild fibrosis in the right lower lobe; however, it is apart from the lung cancer 


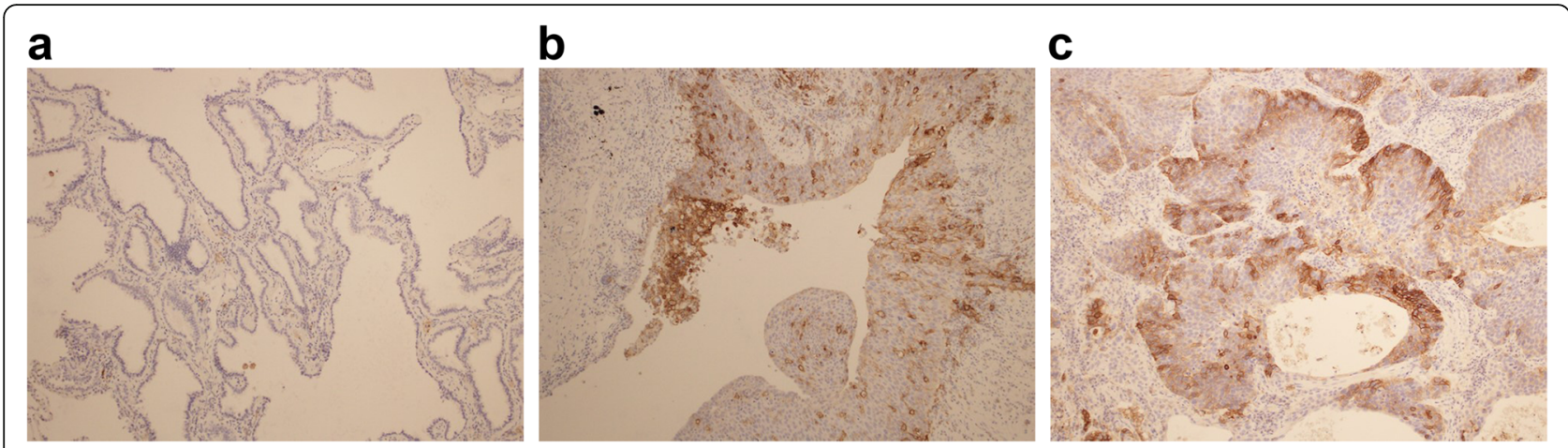

Fig. 4 Examples of programmed cell death ligand 1 expression levels assessed using the 22C3 antibody. a Tumor proportion score $<1 \%$. b Tumor proportion score in the range of $1-49 \%$. c Tumor proportion score $\geq 50 \%$

were located fairly evenly among the upper, middle, and lower lobes. Seven of the eight postoperative AE of IP cases were observed in group A.

\section{Pathological results}

TPS levels of PD-L1 for 68 lung cancers in 64 patients were scored into three levels. In all cases, the independent classifications by the pathologist and the pulmonologist were identical. The numbers of patients with TPS $\geq 50,1-49 \%$, and $0 \%$ were $13(19 \%), 40$ (59\%), and 15 (22\%), respectively.

Table 6 summarizes the analysis of characteristics according to PD-L1 levels. The histological type of cancer differed between the TPS classifications: $11 / 15$ (73\%) of the cancers with TPS of $<1 \%$ were adenocarcinomas, whereas 20/40 (25\%) of the cancers with TPS $1-49 \%$ were adenocarcinomas $(p=0.004)$. Only $2 / 15(13 \%)$ of the cancers with TPS of $<1 \%$ were squamous cell carcinomas, whereas $24 / 40(60 \%)$ of the cancers with TPS 1$49 \%$ were squamous cell carcinomas $(p=0.004)$. None of the patients with TPS of $<1 \%$ were classified into group B, whereas $12 / 40(30 \%)$ and $4 / 13(31 \%)$ of the cancers with TPS $1-49 \%$ and TPS of $>50 \%$ were classified into group B $(p=0.03)$. All postoperative AEs of IP were developed in the patients with TPS of $<1 \%(p=0.015)$.

\section{Discussion}

This study retrospectively investigated clinical, radiological, and pathological characteristics of 120 consecutive patients with NSCLC associated with IP who underwent surgery. Eight (7\%) of the patients experienced postoperative AE of IP, with three of these (38\%) dying. The patients who developed $\mathrm{AE}$ tended to have undergone lobectomy and to have lower $\% \mathrm{VC}$. The fiveyear survival rate of the 46 patients at pathological stage IA was $69 \%$, with only four (9\%) experiencing a recurrence of the lung cancer. We classified the lung cancer with IP into three groups according to the location where the cancer developed by HRCT. Each group showed characteristic features in terms of tumor location, histopathology, PD-L1 expression, and postoperative $\mathrm{AE}$ frequency. To our knowledge, this study is the first to classify lung cancers with IP according to the location of cancer development. Our study findings may help pulmonologists manage patients with resectable lung cancers accompanied with IP.

Studies have reported postoperative AE of IP in patients with NSCLC $[8,16-18]$. In the largest of these [8], 9.3\% of patients experienced postoperative $\mathrm{AE}$, with a mortality rate of $43.9 \%$. In comparison, our results of $7 \%$ with $38 \%$ mortality were marginally better. The relatively low proportion of patients with the UIP pattern in the

Table 1 Patient characteristics

\begin{tabular}{lll}
\hline & Characteristic & All patients $(\boldsymbol{n}=\mathbf{1 2 0})$ \\
\hline Age, years & & $74(50-90)$ \\
Sex & Male/Female & $97 / 23$ \\
Etiology of IP & Idiopathic/Other & $101 / 19$ \\
Clinical diagnosis of IPF & IPF/Non-IPF & $50 / 70$ \\
Surgical approach & VATS/Open surgery & $116 / 4$ \\
Pathological staging & Stage la/lb/lla/llb/ll//V/undetermined & $46 / 27 / 16 / 510 / 2 / 14$ \\
Postoperative adjuvant chemotherapy & Yes/No & $8(6.7 \%) / 112(93.3 \%)$ \\
\hline
\end{tabular}

Data are presented as number or median (range)

IP interstitial pneumonia, IPF idiopathic pulmonary fibrosis, VATS video-assisted thoracic surgery 
Table 2 Clinical summary of the 128 lung cancers

\begin{tabular}{lll}
\hline & & Lung cancers $(\boldsymbol{n}=\mathbf{1 2 8})$ \\
\hline Histological type & Squamous cell carcinoma & $67(52.3 \%)$ \\
& Adenocarcinoma & $46(35.9 \%)$ \\
& Adenosquamous carcinoma & $7(5.5 \%)$ \\
Mutation status & Neuroendocrine carcinoma & $6(4.7 \%)$ \\
& Other & $2(1.6 \%)$ \\
& EGFR mutation positive & $4(3.1 \%)$ \\
\end{tabular}

EGFR epidermal growth factor receptor, $A L K$ anaplastic lymphoma kinase

present study may have influenced this result because the UIP pattern is thought to be a risk factor for developing AE of IP $[8,32]$. In addition, almost all our patients underwent VATS, not open surgery. Although the safety and efficacy of VATS for patients with IP have not yet been established, the high proportion of patients who underwent VATS may have contributed to our good result [15]. Sato et al. proposed a scoring system to predict postoperative AE of IP $[8,33]$, based on a history of AE of IP, the surgical procedure, the UIP pattern, male sex, the preoperative use of steroids, elevated serum Krebs von den Lungen-6 level, and low \%VC. In the present study, the patients who developed AE of IP tended to have undergone lobectomy and to have lower

Table 3 Comparison of patient characteristics between those with and without acute exacerbation of interstitial pneumonia (IP)

\begin{tabular}{|c|c|c|c|c|}
\hline & Characteristic & Without postoperative AE of IP $(n=112)$ & With postoperative AE of IP $(n=8)$ & $P$ \\
\hline Age, years & & $74.5(50-90)$ & $71.5(60-85)$ & N.S. \\
\hline \multirow[t]{2}{*}{ Sex } & Male & 91 & 6 & \\
\hline & Female & 21 & 2 & N.S. \\
\hline \multirow[t]{2}{*}{ Smoking status } & Never & 7 & 0 & \\
\hline & Current or former & 105 & 8 & N.S. \\
\hline Brinkman Index & & $900(0-4400)$ & $850(200-2380)$ & N.S. \\
\hline \multirow[t]{2}{*}{ HRCT IP pattern } & UIP & 52 & 6 & \\
\hline & Non-UIP & 60 & 2 & N.S. \\
\hline \multirow[t]{2}{*}{ Pulmonary emphysema } & Yes & 85 & 7 & \\
\hline & No & 27 & 1 & N.S. \\
\hline \multirow[t]{2}{*}{ Treatment agents for preexisting IP } & Steroids & 5 & 0 & N.S. \\
\hline & Antifibrotic agents & 1 & 0 & N.S. \\
\hline \multirow[t]{6}{*}{ Pulmonary function test results } & $\mathrm{VC}(\mathrm{mL})$ & $3290(1680-5790)$ & 3025 (1920-3910) & N.S. \\
\hline & $\%$ predicted VC & $100.0(55-151)$ & $88.0(82-106)$ & 0.044 \\
\hline & $\mathrm{FVC}(\mathrm{mL})$ & $3290(1560-5790)$ & $2970(1920-3910)$ & N.S. \\
\hline & $\%$ predicted FVC & $102.1(56-162)$ & $92.0(86-114)$ & N.S. \\
\hline & $\%$ predicted $\mathrm{FEV}_{1.0}$ & $69.9(41.5-93.1)$ & $77.6(55.3-82.4)$ & N.S. \\
\hline & $\%$ predicted $\mathrm{DL}_{\mathrm{co}}$ & $74.0(17-133)$ & $63.0(48-116)$ & N.S. \\
\hline \multirow[t]{3}{*}{ Laboratory data } & $\mathrm{KL}-6(\mathrm{U} / \mathrm{mL})$ & $487.0(163-5051)$ & $599.0(233-1386)$ & N.S. \\
\hline & $\mathrm{SP}-\mathrm{D}(\mathrm{ng} / \mathrm{mL})$ & $109.0(21.0-542.0)$ & $156.0(62.1-530.0)$ & N.S. \\
\hline & $\mathrm{SP}-\mathrm{A}(\mathrm{ng} / \mathrm{mL})$ & $49.8(17.4-291.6)$ & $67.3(26.9-143.0)$ & N.S. \\
\hline GAP index* & & $3(0-6)$ & $2.5(1-4)$ & N.S. \\
\hline \multirow[t]{3}{*}{ Surgical procedure } & Lobectomy & 75 & 8 & 0.047 \\
\hline & Segmentectomy & 23 & 0 & N.S. \\
\hline & Wedge resection & 14 & 0 & N.S. \\
\hline
\end{tabular}

Data are presented as number or median (range)

IP interstitial pneumonia, HRCT high-resolution computed tomography, UIP usual interstitial pneumonia, VC vital capacity, FVC forced vital capacity, FEV 1.0 forced expiratory volume in one second, $D L_{C O}$ diffusing capacity for carbon monoxide, $K L-6$ Krebs von den Lungen-6, $S P$ - $D$ surfactant protein $D, S P-A$ surfactant protein $A$, GAP Gender-Age-Physiology, N.S. not significant

* The GAP index was calculated using a multidimensional index and staging system for idiopathic pulmonary fibrosis [28] 


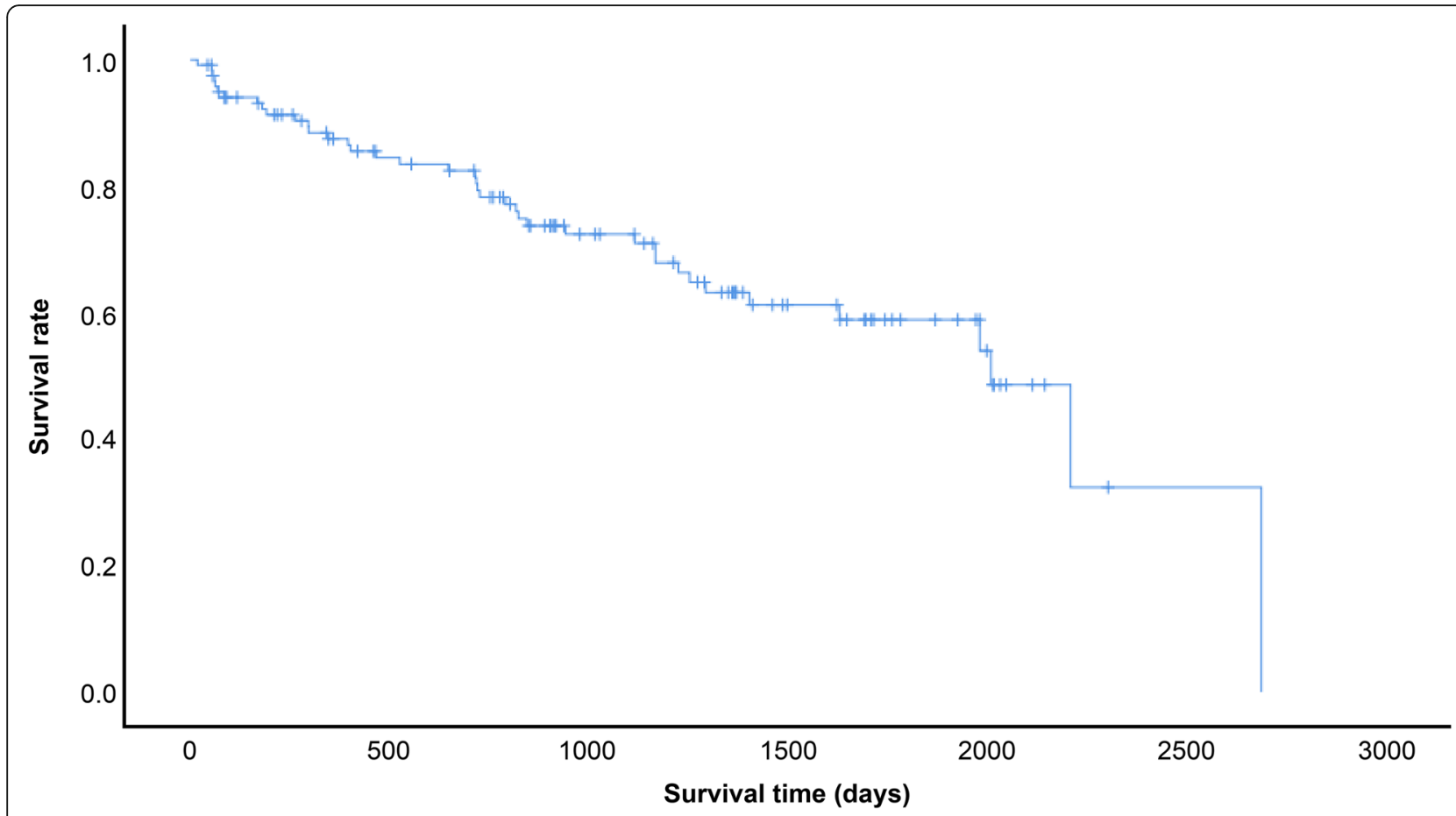

Fig. 5 Survival curve for all 120 patients with non-small-cell lung cancer associated with interstitial pneumonia. The median survival time was 2011 days, and the one-year, three-year, and five-year survival rates were $87.5,72.4$, and 58.9\%, respectively

$\% \mathrm{VC}$; however, \% $\mathrm{VC}$ and lobectomy were the only predictors for AE of IP in this study. This may partially be explained by the small study sample size and partially by the low occurrence rate of $\mathrm{AE}$ of IP.

We also analyzed postoperative treatment and longterm outcomes. When treating patients with advanced or recurrent NSCLC and IP, consideration should be given to the possible $\mathrm{AE}$ of preexisting IP by cancer treatments such as chemotherapy or immunotherapy. In the present study, the most frequently chosen option for the patients who experienced recurrence was best supportive care because of concerns about the AE of IP as a result of chemotherapy $[9,10]$. Of the 46 patients with stage IA cancer, four (9\%) experienced recurrence; this rate is comparable to that of patients without IP [34-
38]. However, the five-year survival rate of the patients with stage I cancer was only $69 \%$. Sato et al. also reported a low 5-year survival rate in 59\% of patients with stage IA NSCLC [39]. These might be explained by the high proportion of patients who received only best supportive care following the recurrence or by the high mortality rate of IP itself. Notably, three patients with stage Ia NSCLC developed postoperative AE of IP. Almost half of the deaths of the patients with NSCLC and IP were owing to IP; thus, the extremely high mortality rate of IP should be considered when developing strategies for these patients.

We classified the lung cancers with IP into three groups, which each showed characteristic features. Group A included cancers located under fibrotic

Table 4 Outcomes for each pathological stage of lung cancer

\begin{tabular}{|c|c|c|c|c|c|c|c|c|}
\hline & $\begin{array}{l}\text { All stages } \\
(\mathrm{N}=120)\end{array}$ & $\begin{array}{l}\text { Stage la } \\
(n=46)\end{array}$ & $\begin{array}{l}\text { Stage Ib } \\
(n=27)\end{array}$ & $\begin{array}{l}\text { Stage lla } \\
(n=16)\end{array}$ & $\begin{array}{l}\text { Stage Illb } \\
(n=5)\end{array}$ & $\begin{array}{l}\text { Stage III } \\
(n=10)\end{array}$ & $\begin{array}{l}\text { Stage IV } \\
(n=2)\end{array}$ & $\begin{array}{l}\text { Undetermined } \\
(n=14)\end{array}$ \\
\hline Recurrence & $29(24.2 \%)$ & $4(8.7 \%)$ & $8(29.6 \%)$ & $8(50.0 \%)$ & $4(80.0 \%)$ & $3(30.0 \%)$ & - & $2(14.3 \%)$ \\
\hline $\begin{array}{l}\text { Induction of chemotherapy } \\
\text { after recurrence }\end{array}$ & $10(34.5 \%)$ & $1(25.0 \%)$ & $2(25.0 \%)$ & $4(50.0 \%)$ & $0(0 \%)$ & $2(66.7 \%)$ & - & $1(50.0 \%)$ \\
\hline Median survival time (days) & 2011 & 2211 & $\begin{array}{l}\text { Not } \\
\text { reached }\end{array}$ & 1116 & 818 & 1404 & 347 & 2011 \\
\hline 1-year survival rate & $87.5 \%$ & $91.0 \%$ & $88.0 \%$ & $93.8 \%$ & $75.0 \%$ & $77.8 \%$ & $50.0 \%$ & $83.3 \%$ \\
\hline 3-year survival arate & $72.4 \%$ & $85.9 \%$ & $74.5 \%$ & $51.1 \%$ & - & $64.8 \%$ & - & - \\
\hline 5-year survival rate & $58.9 \%$ & $69.2 \%$ & $68.8 \%$ & $22.7 \%$ & - & - & - & - \\
\hline
\end{tabular}


Table 5 Clinical and pathological findings for the three groups defined in this study

\begin{tabular}{|c|c|c|c|c|c|}
\hline & Characteristic & $\begin{array}{l}\text { Group A }(n= \\
\text { 89) }\end{array}$ & $\begin{array}{l}\text { Group B }(n= \\
\text { 29) }\end{array}$ & $\begin{array}{l}\text { Group C }(n= \\
10)\end{array}$ & $P$ \\
\hline HRCT IP pattern & UIP /Non-UIP & $49 / 40$ & $11 / 18$ & $0 / 10$ & 0.002 \\
\hline Clinical diagnosis of IPF & IPF/Non-IPF & $41 / 48$ & $10 / 19$ & $0 / 10$ & 0.014 \\
\hline Pulmonary emphysema & Yes/No & $69 / 20$ & $29 / 0$ & $2 / 8$ & $\begin{array}{l}< \\
0.001\end{array}$ \\
\hline $\begin{array}{l}\text { Postoperative acute exacerbation of } \\
\text { IP }\end{array}$ & & 7 & 1 & 0 & N.S. \\
\hline Location of lung cancer & $\begin{array}{l}\text { Upper lobe/Middle lobe/Lower } \\
\text { lobe }\end{array}$ & $11 / 3 / 75$ & $26 / 1 / 2$ & $3 / 4 / 3$ & $\begin{array}{l}< \\
0.001\end{array}$ \\
\hline \multirow[t]{4}{*}{ Histopathology } & Adenocarcinoma & 29 & 9 & 8 & 0.01 \\
\hline & Adenosquamous carcinoma & 4 & 3 & 0 & N.S. \\
\hline & Squamous cell carcinoma & 49 & 16 & 2 & N.S. \\
\hline & Other & 7 & 1 & 0 & N.S. \\
\hline EGFR mutation & Positive & 2 & 0 & 2 & 0.047 \\
\hline
\end{tabular}

Group A cancer associated with fibrotic cysts, group B cancer associated with emphysematous tissue, group $C$ cancer associated with normal lung tissue, IP interstitial pneumonia, HRCT high-resolution computed tomography, UIP usual interstitial pneumonia, IPF idiopathic pulmonary fibrosis, N.S. not significant, EGFR epidermal growth factor receptor

shadows. Group A tended to have squamous cell carcinoma and showed the UIP pattern. Lung cancers were mainly located in the lower lobes in this group. Most cases of postoperative AE of IP were observed in this group. Extremely high attention should be paid to AE of IP when treating patients in this group. Furthermore, some patients with secondary IP and those without UIP were included in group A. Thus, fibrosis leads to lung cancer development regardless of the etiology or radiological pattern of IP. Group C included cancers of normal lung. None of the patients in group $\mathrm{C}$ showed the UIP pattern and most of the cancers were adenocarcinoma. The frequency of epidermal growth factor receptor mutation-positive lung cancer was highest in this group. We speculate that the cancers in this group developed independently from the underlying IP. Driver mutations should always be assessed in this group. Group B included cancers of or near emphysematous tissue. The characteristics of this group were similar to those reported in a previous study of lung cancer

Table 6 Characteristics of the patients according to tumor proportion score for PD-L1

\begin{tabular}{|c|c|c|c|c|}
\hline & PD-L1 < 1\% $(n=15)$ & PD-L1 1-49\% $(n=40)$ & PD-L1 $\geq 50 \%(n=13)$ & $P$ \\
\hline HRCT IP pattern: UIP & 6 & 18 & 4 & N.S. \\
\hline Emphysema & 13 & 31 & 12 & N.S. \\
\hline \multicolumn{5}{|l|}{ Location of the cancer } \\
\hline Upper lobe & 3 & 17 & 3 & N.S. \\
\hline Middle lobe & 2 & 1 & 1 & N.S. \\
\hline Lower lobe & 10 & 22 & 9 & N.S. \\
\hline Group A & 13 & 26 & 8 & N.S. \\
\hline group B & 0 & 12 & 4 & 0.03 \\
\hline group C & 2 & 2 & 1 & N.S. \\
\hline \multicolumn{5}{|l|}{ Pathological findings } \\
\hline Adenocarcinoma & 11 & 10 & 5 & 0.004 \\
\hline Squamous cell carcinoma & 2 & 25 & 6 & 0.004 \\
\hline Other & 2 & 5 & 2 & N.S. \\
\hline EGFR mutation positive & 2 & 0 & 1 & N.S. \\
\hline Postoperative acute exacerbation of IP & 3 & 0 & 0 & 0.015 \\
\hline
\end{tabular}

$\overline{I P}$ interstitial pneumonia, HRCT high-resolution computed tomography, UIP usual interstitial pneumonia, IPF idiopathic pulmonary fibrosis, N.S. not significant, EGFR epidermal growth factor receptor, $P D-L 1$ programmed cell death ligand 1, group $A$ cancer associated with fibrotic cysts, group $B$ cancer associated with

emphysematous tissue, group $C$ cancer associated with normal lung tissue 
associated with emphysema [40]. We speculate that the cancers in this group developed in association with the emphysema. No patients were PD-L1 negative; thus, anti-programmed death-1 or PD-L1 drugs could be used for this group.

Lung cancers in the upper or middle lobes in group A and those in the middle or lower lobes in group B were minority cases (only 17 cases). Among the former 14 cases in group A whose lung cancers developed in the upper or middle lobes, eight had a non-UIP pattern of IP. However, 13 patients had lower-lobe-predominant fibrosis, whereas only one patient had upper-lobe-predominant fibrosis. Only three patients in group B had lung cancers in their middle or lower lobes. Pulmonary emphysema was detected not only in the upper lobes but also in the middle or lower lobes, and lung cancers developed near the emphysema in the middle or lower lobes. The local radiological findings between these minor cases and the rest of the cases had no difference. Hence, fibrosis or emphysema itself can cause lung cancer development irrespective of the location or lobes.

PD-L1 expression in lung cancers was also assessed in this study. The proportion of PD-L1 expression-positive patients was comparable to those reported previously studies [26, 27]. Most cancers with PD-L1 negative were adenocarcinomas, and no patient with PD-L1 negative was classified into group B. All postoperative AE of IP developed in patients with TPS of $<1 \%$. However, we cannot understand the significance of these results owing to the small cohort size. Further studies are needed to understand the mechanism underlying PD-L1 expression.

This study had some strengths; it was one of the largest retrospective studies of NSCLC with IP conducted by a single institution, and it considered long-term outcomes as well as detailed analyses of these patients. However, the study had several limitations. It was a retrospective and single-center study with a relatively small sample size. We did not directly compare patients with IP to patients without IP. A larger, multicenter analysis should be performed to establish clear predictors for the development of postoperative AE of IP.

\section{Conclusions}

We assessed 120 consecutive lung cancer patients with IP and classified them into three groups according to the location where the cancer developed. Each group had characteristic features in terms of tumor location, histopathology, PD-L1 expression, and frequency of postoperative AE. These findings should help inform the treatment of lung cancers associated with IP.

\section{Abbreviations}

AE: Acute exacerbation; GAP: Gender-Age-Physiology index; HRCT: Highresolution computed tomography; IP: Interstitial pneumonia; IPF: Idiopathic pulmonary fibrosis; NSCLC: Non-small cell lung cancer; PD-L1: Programmed cell death ligand 1; TPS: Tumor proportion score; UIP: Usual interstitial pneumonia pattern; \%VC: Percent predicted vital capacity

\section{Acknowledgements}

The authors would like to thank Enago (www.enago.jp) for the English language review.

\section{Authors' contributions}

$\mathrm{KO}$ is the corresponding author. $\mathrm{KO}$ designed this study and analyzed data. $\mathrm{HU}$ and TF mainly contributed to the pathological section and scored PD-L1 expression. SF and TK mainly contributed to the surgery section. All surgeries were performed by them. AK mainly contributed to the radiological section. HRCT findings were reviewed by AK and KO. KK and SA contributed to all parts of this study. They supported to design, analyze, and write this paper. All authors read and approved the final manuscript.

\section{Funding}

This research did not receive any specific grant from funding agencies in the public, commercial, or not-for-profit sectors.

Availability of data and materials

All data generated or analyzed during this study are included in this published article.

Ethics approval and consent to participate

The study was approved by the Institutional Review Board of Toranomon Hospital (1329-H/B and 1447). Patient consent was obtained by using

informed consent documents with an opt-out process.

\section{Consent for publication}

Not applicable.

\section{Competing interests \\ None.}

\section{Author details}

${ }^{1}$ Department of Respiratory Medicine, Respiratory Center, Toranomon Hospital, 2-2-2, Toranomon, Minato-ku, Tokyo, Japan. ${ }^{2}$ Okinaka Memorial Institute for Medical Research, 2-2-2, Toranomon, Minato-ku, Tokyo, Japan. ${ }^{3}$ Department of Respiratory Medicine, Tokyo Medical University, 6-7-1, Nishi-shinjuku, Shinjuku-ku, Tokyo, Japan. ${ }^{4}$ Center for Preventive Medicine, Nomura Hospital, 8-3-6, Shimorenjyaku, Mitaka-shi, Tokyo, Japan.

${ }^{5}$ Department of Pathology, Toranomon Hospital, 2-2-2, Toranomon, Minato-ku, Tokyo, Japan. ${ }^{6}$ Department of Thoracic Surgery, New Tokyo Hospital, 1271, Wanagaya, Matsudo-shi, Chiba, Japan. 'Department of Diagnostic Radiology, Japan Anti-Tuberculosis Association, Fukujuji Hospital, 3-1-24, Matsuyama, Kiyose-shi, Tokyo, Japan. ${ }^{8}$ Department of Respiratory Medicine, Toho University School of Medicine, 6-11-1, Omori-nishi, Ota-ku, Tokyo, Japan.

Received: 14 May 2020 Accepted: 12 November 2020

Published online: 20 November 2020

\section{References}

1. GBD 2015 Mortality and Causes of Death Collaborators. Global, regional, and national life expectancy, all-cause mortality, and cause-specific mortality for 249 causes of death, 1980-2015: a systematic analysis for the Global Burden of Disease Study 2015. Lancet. 2016;388:1459-544.

2. Harris JM, Johnston ID, Rudd R, Taylor AJ, Cullinan P. Cryptogenic fibrosing alveolitis and lung cancer: the BTS study. Thorax. 2010;65:70-6 https://doi. org/10.1136/thx.2009.121962.

3. Tomassetti S, Gurioli C, Ryu JH, Decker PA, Ravaglia C, Tantalocco P, et al. The impact of lung cancer on survival of idiopathic pulmonary fibrosis. Chest. 2015;147:157-64 https://doi.org/10.1378/chest.14-0359.

4. Le Jeune I, Gribbin J, West J, Smith C, Cullinan P, Hubbard R. The incidence of cancer in patients with idiopathic pulmonary fibrosis and sarcoidosis in the UK. Respir Med. 2007:101:2534-40 https://doi.org/10.1016/j.rmed.2007. 07.012 . 
5. Turner-Warwick M, Lebowitz M, Burrows B, Johnson A. Cryptogenic fibrosing alveolitis and lung cancer. Thorax. 1980;35:496-9 https://doi.org/ 10.1136/thx.35.7.496

6. Ozawa Y, Suda T, Naito T, Enomoto N, Hashimoto D, Fujisawa T, et al. Cumulative incidence of and predictive factors for lung cancer in IPF. Respirology. 2009;14:723-8 https://doi.org/10.1111/j.1440-1843.2009.01547.x.

7. Ogura T, Takigawa N, Tomii K, Kishi K, Inoue Y, Ichihara E, et al. Summary of the Japanese respiratory society statement for the treatment of lung cancer with comorbid interstitial pneumonia. Respir Investig. 2019;57:512-33 https://doi.org/10.1016/j.resinv.2019.06.001.

8. Sato T, Teramukai S, Kondo H, Watanabe A, Ebina M, Kishi K, et al. Impact and predictors of acute exacerbation of interstitial lung diseases after pulmonary resection for lung cancer. J Thorac Cardiovasc Surg. 2014;147: 1604-1e3 https://doi.org/10.1016/j.jtcvs.2013.09.050.

9. Minegishi Y, Takenaka K, Mizutani H, Sudoh J, Noro R, Okano T, et al. Exacerbation of idiopathic interstitial pneumonias associated with lung cancer therapy. Intern Med. 2009;48:665-72 https://doi.org/10.2169/ internalmedicine.48.1650.

10. Kenmotsu H, Naito T, Kimura M, Ono A, Shukuya T, Nakamura $Y$, et al. The risk of cytotoxic chemotherapy-related exacerbation of interstitial lung disease with lung cancer. J Thorac Oncol. 2011;6:1242-6 https://doi.org/10. 1097/JTO.0b013e318216ee6b.

11. Kanai O, Kim YH, Demura Y, Kanai M, Ito T, Fujita K, et al. Efficacy and safety of nivolumab in non-small cell lung cancer with preexisting interstitial lung disease. Thorac Cancer. 2018:9:847-55. https://doi.org/. https://doi.org/10. 1111/1759-7714.12759

12. Raghu G, Collard HR, Egan JJ, Martinez FJ, Behr J, Brown KK, et al. An official ATS/ERS/JRS/ALAT statement: idiopathic pulmonary fibrosis: evidence-based guidelines for diagnosis and management. Am J Respir Crit Care Med. 2011; 183:788-824 https://doi.org/10.1164/rccm.2009-040GL.

13. Song JW, Hong SB, Lim CM, Koh Y, Kim DS. Acute exacerbation of idiopathic pulmonary fibrosis: incidence, risk factors and outcome. Eur Respir J. 2011;37:356-63 https://doi.org/10.1183/09031936.00159709.

14. Chiyo M, Sekine Y, Iwata T, Tatsumi K, Yasufuku K, lyoda A, et al. Impact of interstitial lung disease on surgical morbidity and mortality for lung cancer: analyses of short-term and long-term outcomes. J Thorac Cardiovasc Surg. 2003;126:1141-6 https://doi.org/10.1016/s0022-5223(03)00791-8.

15. Koizumi K, Hirata T, Hirai K, Mikami I, Okada D, Yamagishi S, et al. Surgical treatment of lung cancer combined with interstitial pneumonia: the effect of surgical approach on postoperative acute exacerbation. Ann Thorac Cardiovasc Surg. 2004;10:340-6.

16. Kawasaki H, Nagai K, Yoshida J, Nishimura M, Nishiwaki Y. Postoperative morbidity, mortality, and survival in lung cancer associated with idiopathic pulmonary fibrosis. J Surg Oncol. 2002;81:33-7 https://doi.org/10.1002/jso.10145.

17. Fujimoto T, Okazaki T, Matsukura T, Hanawa T, Yamashita N, Nishimura K, et al. Operation for lung cancer in patients with idiopathic pulmonary fibrosis: surgical contraindication? Ann Thorac Surg 2003;76:1674-1678; discussion 1679. https://doi.org/10.1016/s0003-4975(03)00966-4.

18. Watanabe A, Kawaharada N, Higami T. Postoperative acute exacerbation of IPF after lung resection for primary lung cancer. Pulm Med. 2011;2011: 960316 https://doi.org/10.1155/2011/960316.

19. Iwata T, Yoshino I, Yoshida S, Ikeda N, Tsuboi M, Asato Y, et al. A phase II trial evaluating the efficacy and safety of perioperative pirfenidone for prevention of acute exacerbation of idiopathic pulmonary fibrosis in lung cancer patients undergoing pulmonary resection: West Japan oncology group 6711 L (PEOPLE study). Respir Res. 2016;17:90 https://doi.org/10.1186/ s12931-016-0398-4.

20. Sakai S, Ono M, Nishio T, Kawarada Y, Nagashima A, Toyoshima S. Lung cancer associated with diffuse pulmonary fibrosis: CT-pathologic correlation. J Thorac Imaging. 2003;18:67-71 https://doi.org/10.1097/00005382200304000-00002.

21. Yoshida R, Arakawa H, Kaji Y. Lung cancer in chronic interstitial pneumonia: early manifestation from serial CT observations. AJR Am J Roentgenol. 2012; 199:85-90 https://doi.org/10.2214/AJR.11.7516.

22. Oh SY, Kim MY, Kim JE, Kim SS, Park TS, Kim DS, et al. Evolving early lung cancers detected during follow-up of idiopathic interstitial pneumonia: serial CT features. AJR Am J Roentgenol. 2015;204:1190-6 https://doi.org/10. 2214/AJR.14.13587.

23. Lee KJ, Chung MP, Kim YW, Lee JH, Kim KS, Ryu JS, et al. Prevalence, risk factors and survival of lung cancer in the idiopathic pulmonary fibrosis. Thorac Cancer. 2012;3:150-5 https://doi.org/10.1111/j.1759-7714.2011.00107.x.
24. Kishi K, Homma S, Kurosaki A, Motoi N, Yoshimura K. High-resolution computed tomography findings of lung cancer associated with idiopathic pulmonary fibrosis. J Comput Assist Tomogr. 2006;30:95-9 https://doi.org/ 10.1097/01.rct.0000188650.66527.d2.

25. Mizushima Y, Kobayashi M. Clinical characteristics of synchronous multiple lung cancer associated with idiopathic pulmonary fibrosis. A review of Japanese cases. Chest. 1995;108:1272-7 https:/doi.org/10.1378/chest.108.5.1272.

26. Fujimoto D, Sato Y, Morimoto T, Uehara K, Ito M, Otsuka $K$, et al. Programmed cell death ligand 1 expression in non-small-cell lung cancer patients with interstitial lung disease: a matched case-control study. Clin Lung Cancer. 2018;19:e667-73 https://doi.org/10.1016/j.cllc.2018.04.012.

27. Shibaki R, Murakami S, Matsumoto Y, Goto Y, Kanda S, Horinouchi H, et al. Tumor expression and usefulness as a biomarker of programmed death ligand 1 in advanced non-small cell lung cancer patients with preexisting interstitial lung disease. Med Oncol. 2019;36:49 https://doi.org/10.1007/ s12032-019-1274-0.

28. Ley B, Ryerson CJ, Vittinghoff E, Ryu JH, Tomassetti S, Lee JS, et al. A multidimensional index and staging system for idiopathic pulmonary fibrosis. Ann Intern Med. 2012;156:684-91 https://doi.org/10.7326/00034819-156-10-201205150-00004.

29. Collard HR, Ryerson CJ, Corte TJ, Jenkins G, Kondoh Y, Lederer DJ, et al. Acute exacerbation of idiopathic pulmonary fibrosis. An international working group report. Am J Respir Crit Care Med. 2016;194:265-75 https:// doi.org/10.1164/rccm.201604-0801Cl.

30. Travis W, Brambilla E, Burke A, Marx A, Nicholson AG. WHO classification of Tumours of the lung, pleura, Thymus and heart. In: World Health Organization classification of Tumours, vol 7. 4th ed. Lyon, France: International Agency for Research on Cancer; 2015.

31. Edge SB, Compton CC. The American joint committee on Cancer: the 7th edition of the AJCC cancer staging manual and the future of TNM. Ann Surg Oncol. 2010;17:1471-4 https://doi.org/10.1245/s10434-010-0985-4.

32. Kobayashi H, Naito T, Omae K, Omori S, Nakashima K, Wakuda K, et al. Impact of interstitial lung disease classification on the development of acute exacerbation of interstitial lung disease and prognosis in patients with stage iii non-small-cell lung cancer and interstitial lung disease treated with chemoradiotherapy. Cancer. 2018:9:2054-60 https://doi.org/10.7150/jca.24936.

33. Sato T, Kondo H, Watanabe A, Nakajima J, Niwa $H$, Horio $H$, et al. A simple risk scoring system for predicting acute exacerbation of interstitial pneumonia after pulmonary resection in lung cancer patients. Gen Thorac Cardiovasc Surg. 2015;63:164-72 https://doi.org/10.1007/s11748-014-0487-6.

34. Sawabata N, Miyaoka E, Asamura H, Nakanishi Y, Eguchi K, Mori M. Japanese lung cancer registry study of 11,663 surgical cases in 2004: demographic and prognosis changes over decade. J Thorac Oncol. 2011;6:1229-35 https://doi.org/10.1097/JTO.0b013e318219aae2.

35. Engelhardt KE, Odell DD, DeCamp MM. Comparing apples to oranges: short-term mortality after surgery versus stereotactic body radiotherapy for early-stage non-small cell lung cancer. J Thorac Dis. 2018;10:S1974-6 https://doi.org/10.21037/jtd.2018.04.66.

36. Ginsberg RJ, Rubinstein LV. Randomized trial of lobectomy versus limited resection for T1 N0 non-small cell lung cancer. Lung Cancer study group. Ann Thorac Surg. 1995;60:615-22 https://doi.org/10.1016/00034975(95)00537-u.

37. Asamura H, Goya T, Koshiishi Y, Sohara Y, Eguchi K, Mori M, et al. A Japanese lung cancer registry study: prognosis of 13,010 resected lung cancers. J Thorac Oncol. 2008;3:46-52 https://doi.org/10.1097/JTO. Ob013e31815e8577.

38. Shimada Y, Saji H, Yoshida K, Kakihana M, Honda H, Nomura M, et al. Prognostic factors and the significance of treatment after recurrence in completely resected stage I non-small cell lung cancer. Chest. 2013;143: 1626-34 https://doi.org/10.1378/chest.12-1717.

39. Sato T, Watanabe A, Kondo H, Kanzaki M, Okubo K, Yokoi K, et al. Long-term results and predictors of survival after surgical resection of patients with lung cancer and interstitial lung diseases. J Thorac Cardiovasc Surg. 2015; 149:64-70 https://doi.org/10.1016/j.jtcvs.2014.08.086.

40. Smith BM, Schwartzman K, Kovacina B, Taylor J, Kasymjanova G, Brandao G, et al. Lung cancer histologies associated with emphysema on computed tomography. Lung Cancer. 2012;76:61-6 https://doi.org/10.1016/j.lungcan.2011.09.003.

\section{Publisher's Note}

Springer Nature remains neutral with regard to jurisdictional claims in published maps and institutional affiliations. 